Case Report

\title{
Aggressive Differentiated Thyroid Cancer due to EML4e13-ALKe20 Fusion: A Case Presentation and Review of the Literature
}

\author{
Rodhan Khthir (D), ${ }^{1}$ Zainab Shaheen ${ }^{(D)},{ }^{1}$ Prasanna Santhanam, ${ }^{2}$ and Saroj Sigdel ${ }^{1}$ \\ ${ }^{1}$ Marshall University, School of Medicine, Huntington, WV, USA \\ ${ }^{2}$ Johns Hopkins University, School of Medicine, Baltimore, MD, USA \\ Correspondence should be addressed to Rodhan Khthir; rodhan.khthir@sanfordhealth.org
}

Received 5 August 2020; Revised 14 January 2021; Accepted 28 January 2021; Published 15 February 2021

Academic Editor: Toshihiro Kita

Copyright (C) 2021 Rodhan Khthir et al. This is an open access article distributed under the Creative Commons Attribution License, which permits unrestricted use, distribution, and reproduction in any medium, provided the original work is properly cited.

Background. Differentiated thyroid cancer (DTC) is an indolent malignancy. It rarely presents with aggressive local invasion and/or distant metastatic disease. Patient findings. We describe a case of a 30-year-old man with a locally aggressive form of papillary thyroid cancer with EML4e13-ALKe20 fusion (EML4: echinoderm microtubule-associated protein-like 4; ALK: anaplastic lymphoma kinase). He presented with right-side cervical lymphadenopathy with a highly suspicious right-side thyroid nodule. Total thyroidectomy and level IV lymph node resection showed extensive bilateral disease, with extrathyroidal and extranodal extension. FDG-PET CT scan following surgery confirmed the presence of significant residual disease in the neck area. He underwent bilateral lateral lymph node dissection followed by radioactive iodine treatment. Somatic mutation testing showed EML4e13-ALKe20 fusion. Summary. This case represents an aggressive form of DTC with EML4e13-ALKe20 fusion. The rapid progression of clinical signs and symptoms and the local extension beyond the thyroid and lymph nodes with the persistence of high-volume local disease after thyroidectomy highlight the aggressive nature of this mutation and the importance of performing genetic analysis to guide future treatments and determine prognosis. Conclusion. This case highlights the importance of using molecular diagnostics in patient care, especially if the presentation is unusual for DTC. A thorough evaluation of the tumor pathology and the somatic mutational profile analysis are important for obtaining vital therapeutic and prognostic guidance.

\section{Introduction}

Over the last several years, significant progress has been made in understanding the genetic mechanisms behind thyroid cancer and creating molecular tests for diagnosing cancer in thyroid nodules.

$A L K$-associated fusions and point mutations are found in various tumors, including anaplastic large cell lymphoma, non-small-cell cancers (NSCLCs), inflammatory myofibroblastic tumor, diffuse large B-cell lymphoma, esophageal squamous cell carcinoma, renal medullary carcinoma, renal cell carcinoma, breast cancer, colon cancer, and neuroblastoma [1], and serve as diagnostic markers and therapeutic targets. Their role in thyroid cancer is less well established.
We present a case of DTC with EML4e13-ALKe20 fusion with atypical presentation. We conducted a literature review on this rare mutation to better understand its clinical characteristics and potential treatment options.

\section{Case Presentation}

A 30-year-old male with no significant past medical history presented to his primary care physician in early 2019 , with a painless right neck swelling in addition to multiple palpable masses in the area. A neck ultrasound showed multiple irregular and enlarged lymph nodes on the right side of the neck (Figures 1 and 2) along with a calcified right thyroid nodule measuring $17 \times 20 \times 13 \mathrm{~mm}$. The left lobe of the thyroid was normal. The TSH value was 


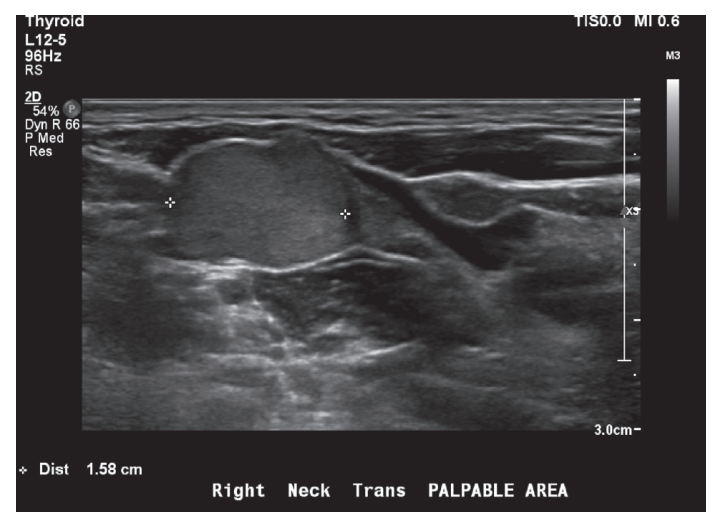

FIGURE 1: Ultrasound transverse image of the right palpable swelling showing abnormal cervical lymph node with localized invasion.

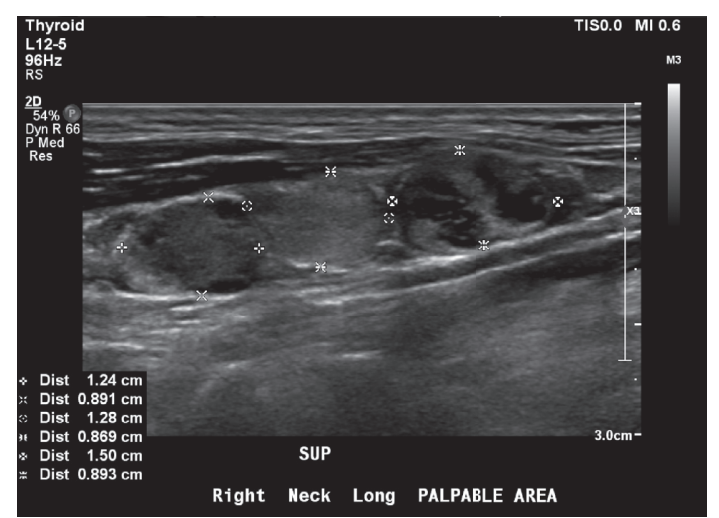

FIGURE 2: Ultrasound transverse image of lymphadenopathy in the right cervical area with distortion of normal morphology and cystic necrosis.

$1.04 \mathrm{mIU} / \mathrm{ml}$, confirming a euthyroid status. The patient reported no history of ionizing radiation exposure and no family history of thyroid cancer or other familial cancer syndromes.

Fine-needle aspiration (FNA) from the palpable lymph node revealed rare atypical epithelial cells and histocytes. Fine-needle aspiration from the right thyroid nodule was performed at an outside facility before referral, and the results were benign (presumably Bethesda class 2). We suspected a sampling error.

Because of the high index of suspicion for thyroid cancer, he underwent total thyroidectomy with central neck dissection and right lateral lymph node dissection at the end of July 2019.

Intraoperative findings showed the presence of extensively involved cervical lymphadenopathy at multiple levels (IV-VI), mainly on the right side. The right cervical level IV and $\mathrm{V}$ lymph nodes were tightly adherent to the internal jugular vein and the other large blood vessels. Abnormal paratracheal lymph nodes were dissected from both sides. Postoperatively, the patient developed right recurrent laryngeal nerve paralysis as there was local invasion around the nerve. However, there was no evidence of postsurgical hypocalcemia.
The histopathology of the resected thyroidectomy specimen showed multifocal follicular variant papillary thyroid cancer (FV-PTC) infiltrating both lobes and the isthmus with angioinvasion, lymphatic invasion, and microscopic extrathyroidal extension (Figure 3 ). The right superior and left superior lobe margins were also positive for the tumor. The largest tumor sizes were 3.5 and $1.5 \mathrm{~cm}$ in the most significant dimension, and the smallest tumor size was $0.1 \mathrm{~cm}$. The Delphian lymph node and $4 / 4$ right level VI lymph nodes had tumor involvement. Left paratracheal nodes (4/4) also had tumor involvement. A total of 5/9 lymph nodes from the right lymph node dissection at levels IV and V had metastatic tumor involvement. The largest metastatic tumor size was $4.0 \mathrm{~cm}$, and this tumor showed an extranodal extension (Figure 4).

On the initial visit to the endocrine clinic four weeks after surgery, a physical exam was remarkable only to develop hoarseness of voice. No palpable lymphadenopathy was noted. The patient was not on thyroid replacement therapy. The thyroglobulin level was $294 \mathrm{ng} / \mathrm{ml} \mathrm{(TSH}$ $52.9 \mathrm{mIU} / \mathrm{ml}$ ). Antithyroglobulin antibodies were undetectable.

Because of the patient's DTC's aggressive nature, nextgeneration sequencing was performed on the tumor tissue (OmniSeq; Integrated Oncology Lab) using multiplexed PCR-based DNA and RNA sequencing. The results showed EML4e13-ALKe20 fusion, a relatively common fusion described in non-small-cell lung cancer, which creates a more tumorigenic $A L K$ kinase domain receptor by partnering with echinoderm microtubule-associated protein-like 4 (EML4) [1]. No other molecular alteration was found. Because of the high thyroglobulin level $(294 \mathrm{ng} / \mathrm{ml}$; TSH $52.9 \mathrm{mIU} / \mathrm{ml})$, which was suggestive of persistent structural disease or distant metastasis, an FDG-PET/CT scan was performed. It showed two hypermetabolic lymph nodes in the upper cervical chain posterior to the internal carotid artery (SUV of 4.9 and 4.4). There was another hypermetabolic lymph node in the left supraclavicular area (SUV of 3.9). There was no significant uptake in the thyroid bed and no evidence of distant metastasis (Figure 5).

The patient underwent a second surgery (bilateral neck dissection for residual disease), and as per the surgeon's description, there was no macroscopic disease left in the explored area. Pathology showed metastatic papillary thyroid cancer in 2 out of 12 right level II lymph nodes and 6 out of 13 left level III lymph nodes. The size of the largest metastatic tumor was $1.3 \mathrm{~cm}$ on both sides. There was evidence of extranodal extension on both sides.

The thyroglobulin level was reduced to $28 \mathrm{ng} / \mathrm{ml} 10$ weeks after the second neck dissection (TSH $83.70 \mathrm{mIU} / \mathrm{ml}$ ). The patient received $150 \mathrm{mCi}$ I-131 therapy for the treatment of remnant tissue and residual disease.

The posttreatment scan showed localized uptake in the neck area (Figure 6).

Four months after posttreatment with radioactive iodine, the thyroglobulin level decreased to $0.19 \mathrm{ng} / \mathrm{ml}$ with undetectable antithyroglobulin antibodies (TSH $0.261 \mathrm{mIU} /$ $\mathrm{ml})$. There was no evidence of local recurrence by physical examination. 


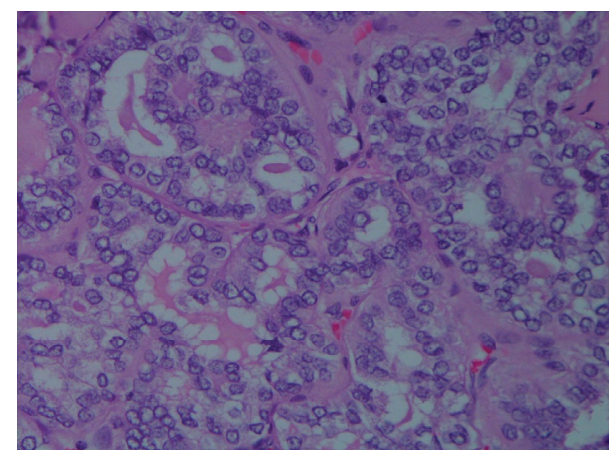

Figure 3: Microscopic examination showing infiltrative tumor with follicular architecture and eosinophilic scalloped colloid. There is overlapping and crowding of tumor cells with cytologic atypia. Numerous pseudoinclusions, nuclear grooves, and ground glass nuclei are also noted.

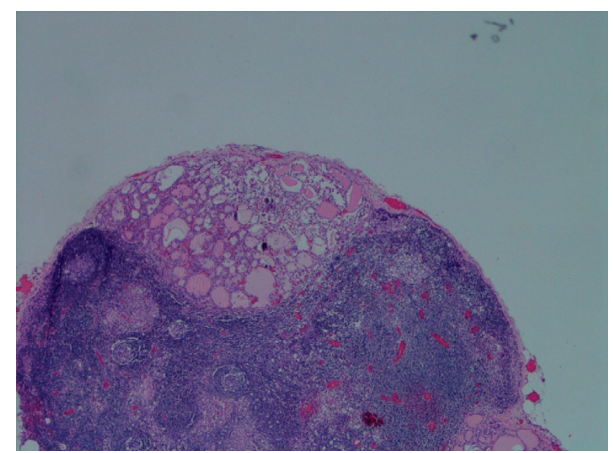

Figure 4: Positive lymph node: the image shows lymph node partially replaced by tumor cells.

\section{Discussion}

The above case represents a highly aggressive form of DTC with an unusual somatic mutation.

Classical molecular abnormalities involving the MAPK (mitogen-activated protein kinase) and PI3K (phosphoinositide 3-kinase) pathways that play a crucial role in follicular-derived thyroid cancer have been previously described [2]. Point mutations in the gene encoding BRAF are the most common genetic alterations in papillary thyroid cancer $[3,4]$. Such mutations are found in $40-60 \%$ of classic papillary thyroid cancers with or without tall cell features, $20-40 \%$ of poorly differentiated thyroid cancers (PDTCs), and $30-40 \%$ of anaplastic thyroid cancers (ATCs). Point mutations in the gene encoding RAS are found in $40-50 \%$ of follicular thyroid cancers and $20-40 \%$ of PDTCs and ATCs [5].

Papillary thyroid cancers are also associated with gene fusion and rearrangements involving receptor tyrosine kinases (RTKs), such as ALK, RET, MET, NTRK, FGFR, and ROS1. The activation of most RTK requires molecular dimerization. Rearrangements of RTK-encoding genes lead to ligand-independent dimerization, which results in the constitutive tyrosine kinase activity and signal transduction to the RAS/RAF/MAPK, PI3K/AKT/mTOR, and JAK-STAT pathways [6]. The chimeric genes resulting from RET rearrangements are referred to as RET/PTC and those resulting from NTRK1 rearrangements as RTK. These gene fusions are prevalent in up to $40 \%$ of sporadic papillary thyroid cancers [7].

Our patient has an aggressive DTC with a less common gene fusion involving the ALK gene (EML4e13-ALKe20 fusion). ALK fusion proteins have been shown to activate various signaling pathways, among which are the phosphtidylinositol 3-kinase (PI3K)/Akt pathway and the Ras $\longrightarrow$ Raf $\longrightarrow$ MEK $\longrightarrow$ ERK (MAP kinase) pathway with multiple interaction points to mediate the ALK signaling. Such fusion promotes ligand-independent signaling and increases growth and cell invasion [1].

EML4 is a member of the echinoderm microtubuleassociated protein-like family. The gene encodes a WDrepeat-containing protein that may be involved in microtubule formation. An abnormal fusion of parts of this gene with portions of the anaplastic lymphoma receptor tyrosine kinase gene generates EML4-ALK fusion transcripts.

The ALK gene encodes a receptor tyrosine kinase that belongs to the insulin receptor superfamily (https://www. genecards.org/Search/Keyword?queryString=ALK\%20EML). This protein comprises an extracellular domain, a hydrophobic stretch corresponding to the single-pass transmembrane region, and an intracellular kinase domain. It appears to play an important role in the development of the brain and exerts its effects on specific neurons in the nervous system. Chromosomal rearrangements are the most common genetic alterations in this gene and result in the creation of multiple fusion genes which act as oncogenes, leading to constitutive autophosphorylation and activation of ALK tyrosine kinase. For reasons that are not currently understood, it seems that ALK locus is prone for translocation. Nearly 30 different $A L K$ gene rearrangements have been described, few of which have been extensively studied like NPM1 (5q35)/ALK (2p23), which was the first identified $A L K$ fusion to nucleophosmin (NPM1) in anaplastic large cell lymphoma [8] and EML4 (2p21)/ALK (2p23) in non-small-cell lung cancer [9, 10]. $E M L 4-A L K$ in non-small-cell lung cancer (NSCLC) serves as a diagnostic marker and therapeutic target. Advanced NSCLC associated with the $A L K$ fusion oncogene is highly sensitive to ALK tyrosine kinase inhibitors (TKIs), such as ceritinib, alectinib, and brigatinib [11, 12].

Other described fusion genes are RANBP2(2q12)/ $A L K(2 p 23)$ associated with inflammatory myofibroblastic tumors; $\operatorname{ATIC}(2 q 35) / A L K(2 p 23), T F G(3 q 12) / A L K(2 p 23)$, and $M S N(X q 12) / A L K(2 p 23)$ associated with anaplastic large cell lymphoma; SQSTM1(5q35)/ALK(2p23) associated with ALKpositive large B-cell lymphoma; KIF5B(10p11)/ALK(2p23) associated with NSCLC; $\operatorname{STRN}(2 p 22) / A L K(2 p 23)$ associated 


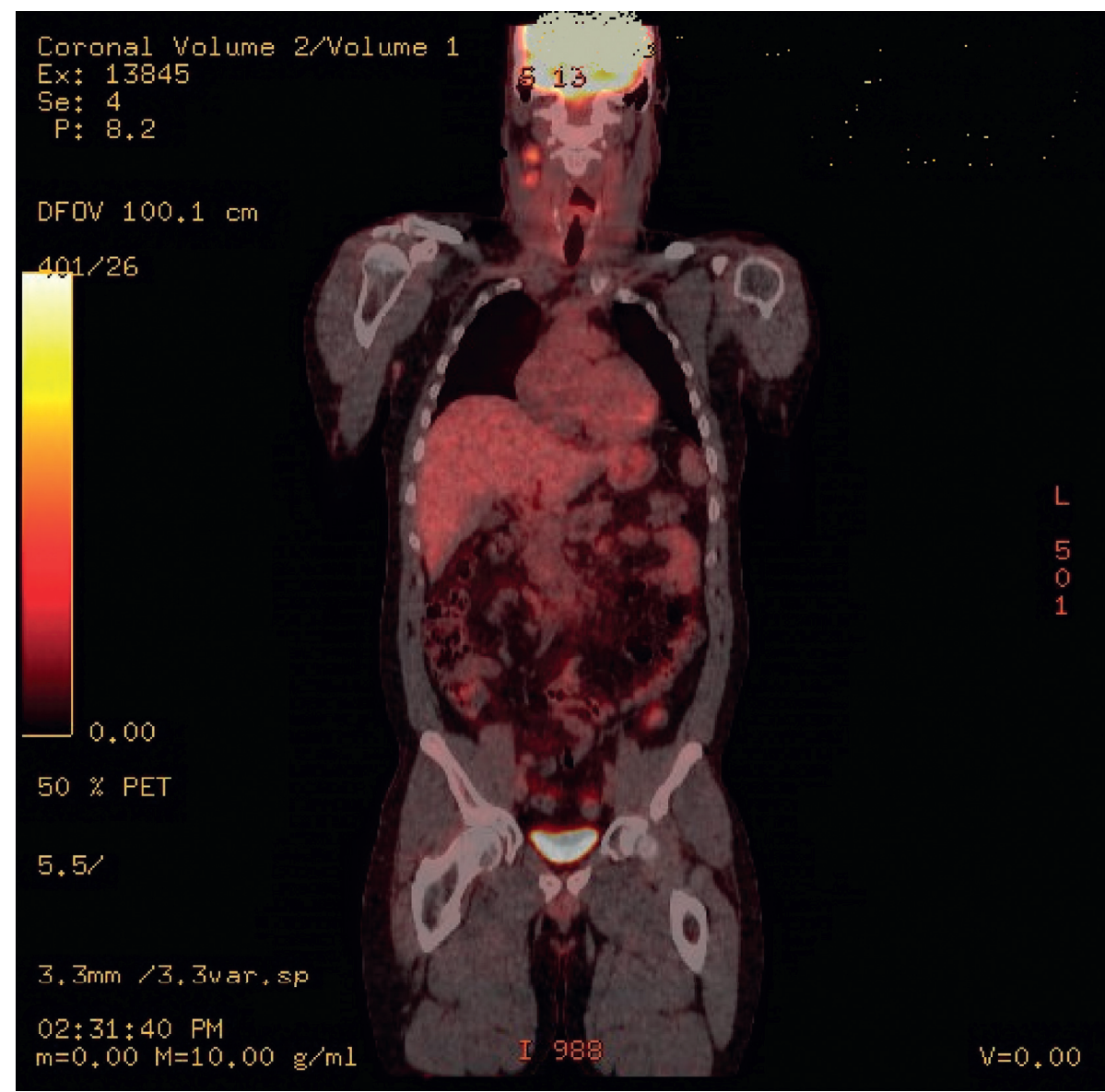

FIGURE 5: FDG-PET scan showing increase in uptake in two upper cervical lymph nodes.

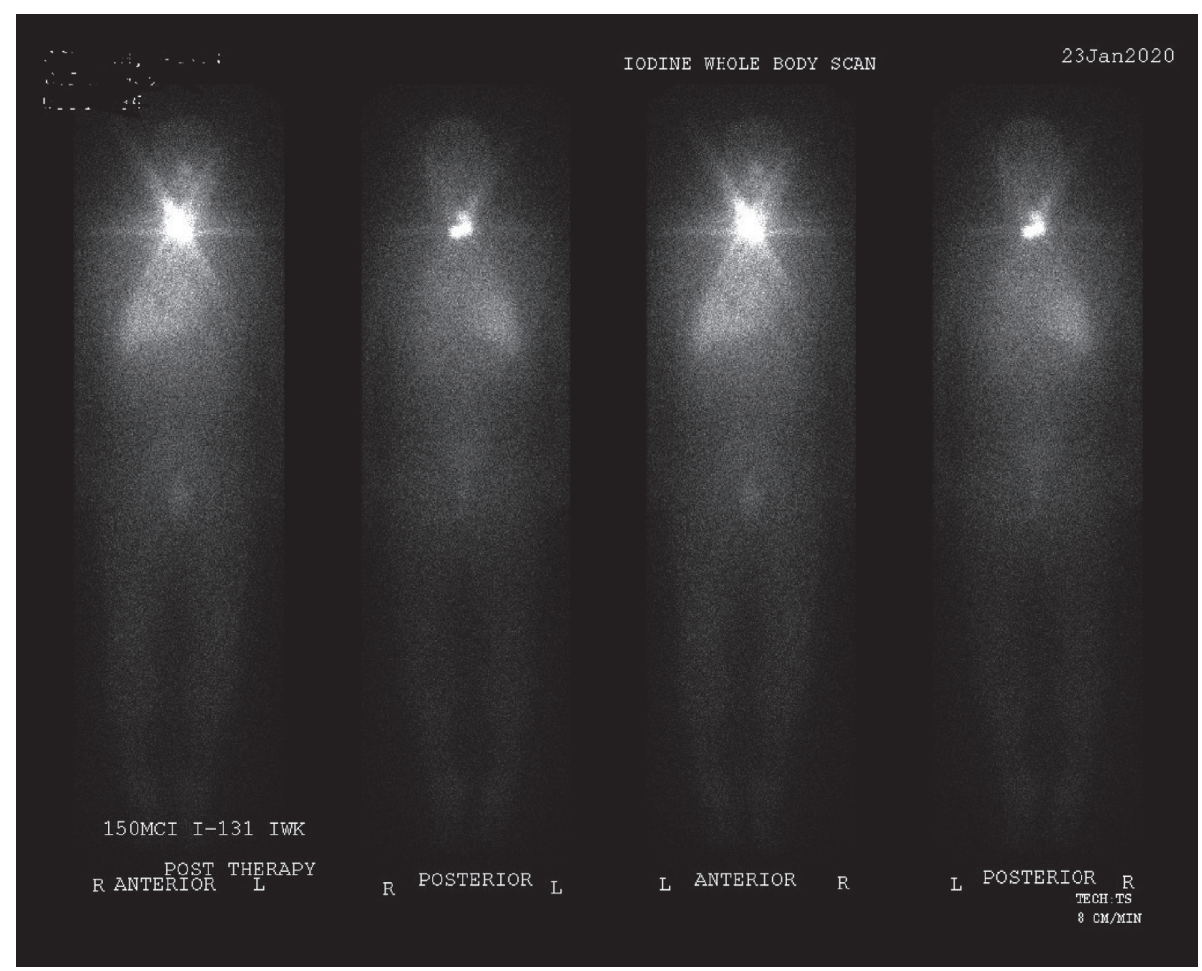

Figure 6: Whole body scan, one week posttreatment with $150 \mathrm{mCi} \mathrm{I-131.} \mathrm{It} \mathrm{shows} \mathrm{localized} \mathrm{uptake} \mathrm{in} \mathrm{the} \mathrm{neck} \mathrm{area} \mathrm{with} \mathrm{no} \mathrm{evidence} \mathrm{of}$ distant metastasis. 
TABle 1: Prevalence of EML4/ALK fusion.

\begin{tabular}{|c|c|c|c|c|c|c|c|c|}
\hline $\begin{array}{l}\text { Author } \\
\text { (reference) }\end{array}$ & Year & Country & $\begin{array}{c}\text { Study } \\
\text { population }\end{array}$ & $\begin{array}{l}\text { Sample } \\
\text { size }\end{array}$ & $\begin{array}{l}\text { Number of persons } \\
\text { with kinase gene } \\
\text { rearrangement }(\%)\end{array}$ & $\begin{array}{c}\text { Patients with } \\
E M L 4 / A L K \\
\text { (number) }\end{array}$ & Findings & $\begin{array}{l}\text { Follow-up } \\
\text { (months) }\end{array}$ \\
\hline Chu et al. [6] & 2020 & USA & $\begin{array}{c}\text { PTC, PDTC, } \\
\text { ANC }\end{array}$ & 395 & $62(16 \%)$ & 1 & $\begin{array}{l}\text { Association seen } \\
\text { between kinase gene } \\
\text { fusion and clinical } \\
\text { aggressiveness }\end{array}$ & $6-480$ \\
\hline $\begin{array}{l}\text { Hamatani } \\
\text { et al. [14] }\end{array}$ & 2012 & Japan & $\begin{array}{l}\text { Atomic bomb } \\
\text { survivors with } \\
\text { PTC }\end{array}$ & 105 & $10(10 \%)$ & 6 & $\begin{array}{l}\text { ALK fusion associated } \\
\text { with radiation }\end{array}$ & NA \\
\hline $\begin{array}{l}\text { Agrawal et al. } \\
{[15]}\end{array}$ & 2014 & USA & $\begin{array}{l}\text { Patients with } \\
\text { PTC }\end{array}$ & 496 & $74(15 \%)$ & 4 & $\begin{array}{c}>96 \% \text { of PTCs have } \\
\text { driver oncogenic } \\
\text { mutation }\end{array}$ & NA \\
\hline $\begin{array}{l}\text { Kelly et al. } \\
{[16]}\end{array}$ & 2014 & USA & PTC & 256 & $4(2 \%)$ & 1 & $\begin{array}{l}\text { Compared to EML4- } \\
\text { ALK, STRN-ALK is } \\
\text { more common in } \\
\text { PDTC }\end{array}$ & NA \\
\hline $\begin{array}{l}\text { Panebianco } \\
\text { et al. [17] }\end{array}$ & 2019 & USA & $\begin{array}{l}\text { PTC and } \\
\text { PDTC }\end{array}$ & 44 & $44(100 \%)$ & 17 & $\begin{array}{l}\text { Compared to EML4- } \\
\text { ALK, STRN-ALK is } \\
\text { more common in } \\
\text { PDTC }\end{array}$ & 2-108 months \\
\hline
\end{tabular}

$\mathrm{PTC}=$ papillary thyroid cancer; $\mathrm{ATC}=$ anaplastic thyroid cancer; $\mathrm{PDTC}=$ poorly differentiated thyroid cancer.

with DTC and breast cancer; CLTC(17q23)/ALK(2p23) and TPM4(19p13)/ALK(2p23) associated with anaplastic large cell lymphoma and inflammatory myofibroblastic tumors [13] (https://https://www.genecards.org/Search/Keyword? queryString=ALK\%20EML); and Atlas of Genetics and Cytogenetics in Oncology and Haematology (atlasgeneticsoncology.org).

Our case's presentation was atypical for a well-differentiated FV-PTC in many aspects, including the rapid progression of clinical symptoms and signs, the extension beyond the thyroid and lymph nodes, and the persistence of high-volume local disease after thyroidectomy. Mutation analysis of the tumor tissue showed the presence of EML4e13-ALKe20 fusion.

EML4-ALK fusion in thyroid cancer was first described in relation to exposure to ionizing radiation [14]. Hamatani et al. explored $E M L 4 / A L K$ and other $A L K$ rearrangements in Atomic Bomb Survivors (ABS) of Hiroshima and Nagasaki who were diagnosed with PTC between 1956 and 1993. In the 25 ABS survivors with PTC with no detectable gene alteration in $B R A F, R A S, R E T$, or NTRK1, ALK rearrangement was found in 10 out of 19 radiation-exposed PTCs (see Table 1). Five PTC cases with rearranged $A L K$ were a fusion of EML4 (exon 13) and ALK (exon 20), one case was a fusion of EML4 (exon 20) and ALK (exon 20), and $A L K$ partner genes in four cases have not been determined by the time of the publication and none in 6 patients with PTC without radiation exposure. Besides, solid/trabecular-like architecture in PTC was closely associated with $A L K$ rearrangement in this cohort, being observed in 6 of 10 PTC cases with $A L K$ rearrangements versus 2 of 15 cases with no $A L K$ rearrangements [14].

Agrawal et al. in The Cancer Genome Atlas (TCGA) project performed a comprehensive multiplatform analysis of 496 PTCs. Fusions involving $A L K$ presented in $4 / 484$ (0.8\%) tumors, including EML4/ALK [15].

Kelly et al. screened a total of 256 well-differentiated PTCs using whole-transcriptome RNA-sequencing analysis. The overall frequency of $A L K$ fusion was four (1.6\%) in 256 samples. EML4-ALK fusion was found in one tumor, and $A L K$ fusions involving the striatin gene (STRN-ALK) were found in 3 tumors. In comparison, STRN-ALK was detected in three of 35 PDTCs (9\%) and one of 24 ATCs (4\%). All detected $A L K$ fusions were $S T R N-A L K$, and no additional cases of EML4-ALK were found [16].

Panebianco et al. showed in a series of 44 ALK-translocated thyroid neoplasms that $A L K$ fusion-positive thyroid carcinomas are typically infiltrative PTCs with a common follicular growth pattern and may show tumor dedifferentiation, which is associated with increased mortality. The most common ALK fusion partners were STRN $(n=22)$ and EML4 $(n=17)$. In 5 cases, novel $A L K$ fusion partners were discovered. All 5 PDTCs carried the STRN-ALK fusion. Compared to EML4-ALK, STRN-ALK may be more common in PDTC, and $\sim 10 \%$ of $A L K$ fusions involve rare gene partners [17]. In the same study, Panebianco et al. showed that all 19 resected thyroid nodules with $A L K$ fusions identified preoperatively by fine-needle aspiration were malignant [17].

Chu et al. investigated the correlation between genotype and tumor behavior in 62 kinase fusion-positive thyroid carcinomas, including 57 papillary thyroid carcinomas (PTCs), two poorly differentiated thyroid carcinomas (PDTCs), two undifferentiated thyroid carcinomas (ATCs), and one primary secretory carcinoma (SC). ALK rearrangements were found in one PDTC and two PTCs. The two PTCs, despite having different fusion partners (STRN and EML4), were morphologically similar (with multinodular growth and predominantly follicular architecture) [6]. 
Point mutation of $A L K$ gene has been reported by Murugan and Xing, who identified two novel point mutations in exon 23 of the ALK gene, C3592T and G3602A, in patients with anaplastic thyroid cancer with a prevalence of $11.11 \%$ but found no mutations in the matched normal tissues or in well-differentiated thyroid cancer [18].

\section{Conclusion}

In summary, we presented a patient with aggressive DTC with a less common gene fusion involving the $A L K$ gene (EML4e13-ALKe20 fusion). Identification of $A L K$ rearrangement in thyroid tumor is of particular interest due to crizotinib's effectiveness and other specific ALK inhibitors that have been shown to induce a remarkable response in one case of aggressive PTC and ATC $[18,19]$. Kelly et al. demonstrated that crizotinib effectively inhibits thyroid cell proliferation driven by $S T R N-A L K$, raising the possibility that $A L K$ may serve as a therapeutic target for thyroid cancer [16]. Godbert et al. demonstrated a remarkable response to crizotinib in women with anaplastic lymphoma kinase-rearranged anaplastic thyroid carcinoma [20].

Precision medicine is an emerging approach for disease management that considers individual variability in presentation, progression, and response to treatment. Genetic mutation analysis and molecular markers are the cornerstones of precision medicine in cancer treatment, as many of these mutations are considered therapeutic targets for modern cancer medications.

The selective use of molecular diagnostics can help with DTC management, especially in patients with atypical presentations or more aggressive clinical courses.

\section{Data Availability}

All data generated or analyzed during this study are included in this published article or in the data repositories listed in references.

\section{Conflicts of Interest}

The authors declare that there are no conflicts of interest.

\section{References}

[1] B. Hallberg and R. H. Palmer, "The role of the ALK receptor in cancer biology," Annals of Oncology, vol. 27, no. 3, pp. iii4-iii15, 2016.

[2] B. R. Haugen, E. K. Alexander, K. C. Bible et al., "2015 American thyroid association management guidelines for adult patients with thyroid nodules and differentiated thyroid cancer: the American thyroid association guidelines task force on thyroid nodules and differentiated thyroid cancer," Thyroid, vol. 26, no. 1, pp. 1-133, 2016.

[3] D. Chakravarty, E. Santos, M. Ryder et al., "Small-molecule MAPK inhibitors restore radioiodine incorporation in mouse thyroid cancers with conditional BRAF activation," Journal of Clinical Investigation, vol. 121, no. 12, pp. 4700-4711, 2011.

[4] J. A. Knauf, X. Ma, E. P. Smith et al., "Targeted expression of BRAFV600E in thyroid cells of transgenic mice results in papillary thyroid cancers that undergo dedifferentiation," Cancer Research, vol. 65, no. 10, pp. 4238-4245, 2005.

[5] K. A. Miller, N. Yeager, K. Baker, X.-H. Liao, S. Refetoff, and A. Di Cristofano, "Oncogenic Kras requires simultaneous PI3K signaling to induce ERK activation and transform thyroid epithelial cells in vivo," Cancer Research, vol. 69, no. 8, pp. 3689-3694, 2009.

[6] Y.-H. Chu, L. J. Wirth, A. A. Farahani et al., "Clinicopathologic features of kinase fusion-related thyroid carcinomas: an integrative analysis with molecular characterization," Modern Pathology, vol. 33, no. 12, pp. 2458-2472, 2020.

[7] I. Bongarzone, P. Vigneri, L. Mariani, P. Collini, S. Pilotti, and M. A. Pierotti, "RET/NTRK1 rearrangements in thyroid gland tumors of the papillary carcinoma family: correlation with clinicopathological features," Clinical Cancer Research, vol. 4, no. 1, p. 223, 1998.

[8] S. Morris, M. Kirstein, M. Valentine et al., "Fusion of a kinase gene, ALK, to a nucleolar protein gene, NPM, in nonHodgkin's lymphoma," Science, vol. 263, no. 5151, pp. 1281-1284, 1994.

[9] M. Soda, Y. L. Choi, M. Enomoto et al., "Identification of the transforming EML4-ALK fusion gene in non-small-cell lung cancer," Nature, vol. 448, no. 7153, pp. 561-566, 2007.

[10] T. Takahashi, M. Sonobe, M. Kobayashi et al., "Clinicopathologic features of non-small-cell lung cancer with EML4ALK fusion gene," Annals of Surgical Oncology, vol. 17, no. 3, pp. 889-897, 2010.

[11] A. T. Shaw and B. Solomon, "Targeting anaplastic lymphoma kinase in lung cancer: figure 1," Clinical Cancer Research, vol. 17, no. 8, pp. 2081-2086, 2011.

[12] L. A. Pikor, V. R. Ramnarine, S. Lam, and W. L. Lam, "Genetic alterations defining NSCLC subtypes and their therapeutic implications," Lung Cancer, vol. 82, no. 2, pp. 179-189, 2013.

[13] Z. Cao, Q. Gao, M. Fu, N. Ni, Y. Pei, and W.-B. Ou, "Anaplastic lymphoma kinase fusions: roles in cancer and therapeutic perspectives," Oncology Letters, vol. 17, no. 2, pp. 2020-2030, 2019.

[14] K. Hamatani, M. Mukai, K. Takahashi, Y. Hayashi, K. Nakachi, and Y. Kusunoki, "Rearranged anaplastic lymphoma kinase (ALK) gene in adult-onset papillary thyroid cancer amongst atomic bomb survivors," Thyroid, vol. 22, no. 11, pp. 1153-1159, 2012.

[15] Cancer Genome Atlas Research Network, "Integrated genomic characterization of papillary thyroid carcinoma- genome Atlas research network," Cell, vol. 159, no. 3, pp. 676-690, 2014.

[16] L. M. Kelly, G. Barila, P. Liu et al., "Identification of the transforming STRN-ALK fusion as a potential therapeutic target in the aggressive forms of thyroid cancer," Proceedings of the National Academy of Sciences, vol. 111, no. 11, pp. 4233-4238, 2014.

[17] F. Panebianco, A. V. Nikitski, M. N. Nikiforova et al., "Characterization of thyroid cancer driven by known and novel ALK fusions," Endocrine-Related Cancer, vol. 26, no. 11, pp. 803-814, 2019.

[18] A. K. Murugan and M. Xing, "Anaplastic thyroid cancers harbor novel oncogenic mutations of the ALK gene," Cancer Research, vol. 71, no. 13, pp. 4403-4411, 2011.

[19] M. J. Demeure, M. Aziz, R. Rosenberg, S. D. Gurley, K. J. Bussey, and J. D. Carpten, "Whole-genome sequencing of an aggressive BRAF wild-type papillary thyroid cancer identified EML4-ALK translocation as a therapeutic target," World Journal of Surgery, vol. 38, no. 6, pp. 1296-1305, 2014. 
[20] Y. Godbert, B. Henriques de Figueiredo, F. Bonichon et al., "Remarkable response to crizotinib in woman with anaplastic lymphoma kinase-rearranged anaplastic thyroid carcinoma," Journal of Clinical Oncology, vol. 33, no. 20, pp. e84-e87, 2015. 